\title{
Physicochemical Properties of Epoxy Resin-Based and Bioceramic-Based Root Canal Sealers
}

\author{
Ju Kyung Lee, ${ }^{1}$ Sang Won Kwak, ${ }^{1}$ Jung-Hong Ha, ${ }^{2}$ WooCheol Lee, ${ }^{3}$ and Hyeon-Cheol Kim ${ }^{1}$ \\ ${ }^{1}$ Department of Conservative Dentistry, School of Dentistry, Pusan National University, Dental Research Institute, \\ Yangsan, Republic of Korea \\ ${ }^{2}$ Department of Conservative Dentistry, School of Dentistry, Kyungpook National University, Daegu, Republic of Korea \\ ${ }^{3}$ Department of Conservative Dentistry, Seoul National University School of Dentistry, Seoul, Republic of Korea \\ Correspondence should be addressed to Hyeon-Cheol Kim; golddent@pusan.ac.kr
}

Received 30 September 2016; Accepted 8 December 2016; Published 22 January 2017

Academic Editor: Jong R. Kim

Copyright (C) 2017 Ju Kyung Lee et al. This is an open access article distributed under the Creative Commons Attribution License, which permits unrestricted use, distribution, and reproduction in any medium, provided the original work is properly cited.

\begin{abstract}
Three bioceramic sealers (EndoSequence BC sealer, EndoSeal MTA, and MTA Fillapex) and three epoxy resin-based sealers (AHPlus, AD Seal, and Radic-Sealer) were tested to evaluate the physicochemical properties: flow, final setting time, radiopacity, dimensional stability, and $\mathrm{pH}$ change. The one-way ANOVA and Tukey's post hoc test were used to analyze the data $(P=0.05)$. The MTA Fillapex sealer had a highest flow and the BC Sealer presented a flow significantly lower than the others $(P<0.05)$. The BC Sealer and MTA Fillapex samples were not set in humid incubator condition even after one month. EndoSeal MTA had the longest setting time among the measurable materials and Radic-Sealer and AD Seal showed shorter setting time than the AH-Plus $(P<$ 0.05). AH-Plus and EndoSeal MTA showed statistically higher values and MTA Fillapex showed statistically lower radiopacity $(P<$ 0.05). BC Sealer showed the highest alkaline $\mathrm{pH}$ in all evaluation periods. Set samples of 3 epoxy resin-based sealers and EndoSeal MTA presented a significant increase of $\mathrm{pH}$ over experimental time for 4 weeks. In conclusion, the bioceramic sealer and epoxy resin-based sealers showed clinical acceptable physicochemical properties, but BC Sealer and MTA Fillapex were not set completely.
\end{abstract}

\section{Introduction}

Endodontic sealers are used to attain a fluid-proof seal throughout root canal system [1]. An ideal root canal sealer should offer an excellent seal when set, dimensional stability, a sufficient setting time to ensure working time, insolubility against tissue fluids, proper adhesion with canal walls, and biocompatibility $[2,3]$.

The commercially available sealers are categorized according to chemical components: zinc-oxide eugenol, calcium hydroxide containing, resin-based, glass-ionomerbased, silicone-based, and bioceramic-based sealers [4-6]. Epoxy resin-based sealers were introduced in endodontics by Schroeder [7], and current modifications of the original formula are widely used for root canal filling procedures $[8,9]$. Recently, bioceramic-based materials such as EndoSequence BC Sealer (Brasseler USA, Savannah, GA), EndoSeal MTA (MARUCHI, Wonju, Korea), and MTA Fillapex (Angelus Soluções Odontológicas, Londrina, PR,
Brazil) have received considerable attention because of their favorable physicobiological properties $[10,11]$. Among them, EndoSequence BC Sealer and EndoSeal MTA are supplied in a premixed injectable paste and thus give clinicians easy manipulation. These currently introduced calcium silicate based sealers still have few reports about their chemical and physical properties $[3,10,12]$.

This study aimed to evaluate the physicochemical properties of 3 epoxy resin-based sealers and 3 bioceramicbased sealers according to the international standards such as ISO 6876/2012 standards [13] and ANSI/ADA's specifications number 57 [14] (Table 1).

\section{Materials and Methods}

Three epoxy resin-based root canal sealers of AH-Plus, AD Seal, and Radic-Sealer and 3 bioceramic-based sealers of EndoSequence BC Sealer, EndoSeal MTA, and MTA Fillapex were used as the experimental materials (Figure 1, Table 2). 
TABLE 1: ISO 6876/2012 and ANSI/ADA specification number 57 standards.

\begin{tabular}{|c|c|c|}
\hline & ISO standards & ANSI/ADA standards \\
\hline Setting time & $\begin{array}{l}\text { When } \leq 30 \mathrm{~min}, \leq 110 \% \text { stated by the manufacture } \\
\text { When }>30 \mathrm{~min},<72 \text { hours, within the range (min) }\end{array}$ & $\begin{array}{l}\text { Within } 10 \% \text { of setting time stated by the } \\
\text { manufacturers }\end{array}$ \\
\hline Flow & $\geq 20 \mathrm{~mm}$ & $\geq 25 \mathrm{~mm}$ \\
\hline Solubility & $\leq 3 \%$ for 24 hours & $\leq 3 \%$ for 24 hours \\
\hline Dimensional change & \multicolumn{2}{|c|}{ Shrinkage (contraction) $\leq 1 \%$ for 30 days } \\
\hline Radiopacity & \multicolumn{2}{|c|}{$\geq 3 \mathrm{~mm}$ aluminum thickness } \\
\hline
\end{tabular}

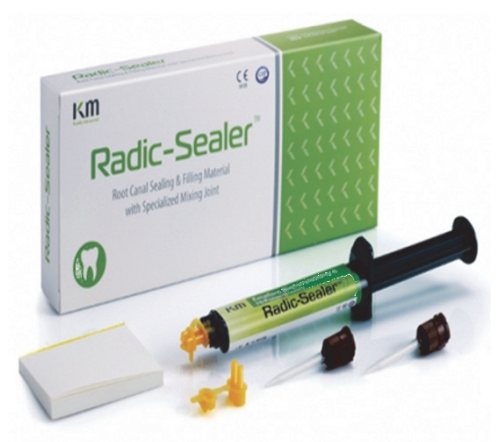

(a)

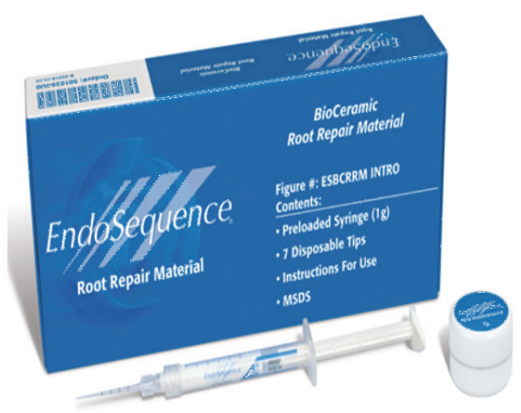

(d)

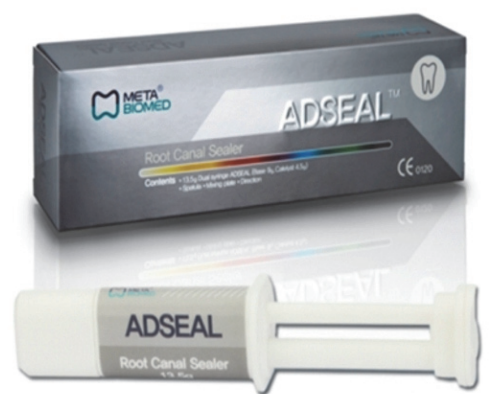

(b)

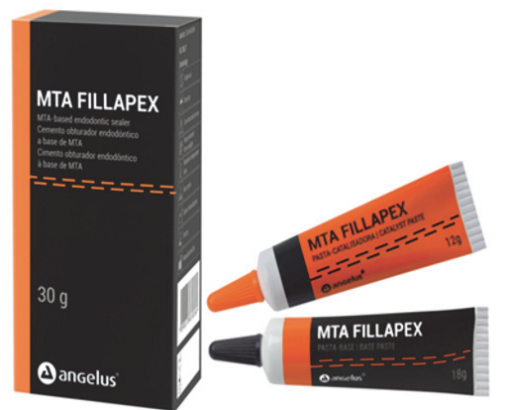

(e)

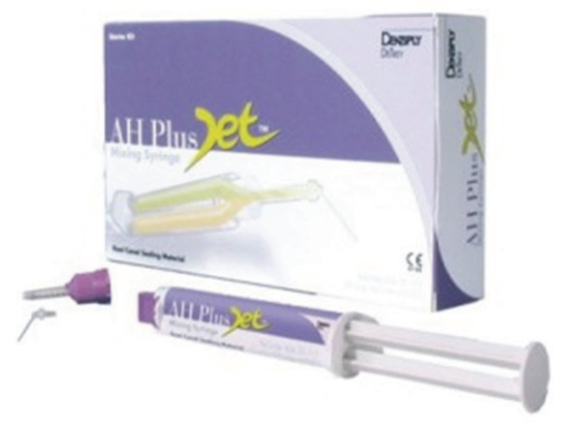

(c)

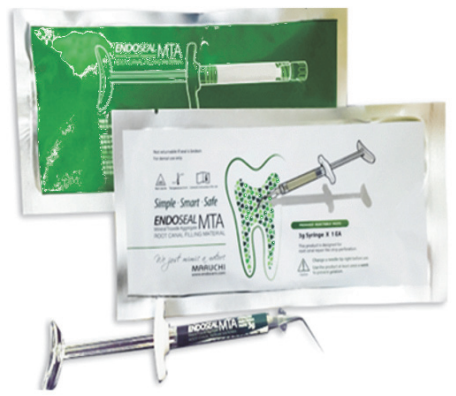

(f)

Figure 1: Six root canal sealers tested in the present study: (a) Radic-Sealer, (b) AD Seal, (c) AH-Plus, (d) EndoSequence BC Sealer, (e) MTA Fillapex, and (f) EndoSeal MTA.

AH-Plus (Dentsply DeTrey, Konstanz, Germany) is the most popular hydrophobic epoxy resin-based sealer that has been used as the gold standard material [3]. AD Seal (Meta Biomed, Cheongju, Korea) and Radic-Sealer (KM, Seoul, Korea) are the epoxy resin-based sealers with few reports in literature $[15,16]$.

The physicochemical properties including flow, final setting time, radiopacity, dimensional stability, and $\mathrm{pH}$ change were examined according to modified ISO 6876/2012 standards [13] and ANSI/ADA's specifications number 57 [14]. All sealers were mixed and manipulated depending on the manufacturers' instructions.

2.1. Flow. A volume of $0.05 \mathrm{~mL}$ mixed sealer was dropped on a glass plate. At 3 minutes after the onset of mixing, a second glass plate was placed on the sealer and a $100 \mathrm{~g}$ weight was added to make a total mass of $120 \mathrm{~g}$. The $120 \mathrm{~g}$ weight was unloaded after 10 minutes from the start of mixing. The minimum and maximum diameters of the sealer disc were measured by a digital caliper (Mitutoyo Corp, Tokyo, Japan) with a resolution of $0.01 \mathrm{~mm}$. If the disks were not uniformly circular, the test was repeated. Ten tests were taken for each sealer.

2.2. Final Setting Time. Stainless steel ring molds (inner diameter $10 \mathrm{~mm}$, height $2 \mathrm{~mm}$ ) were placed on a glass plate, and then the sealer materials were mixed and packed into the molds. The whole assembly was then stored in an incubator $\left(37^{\circ} \mathrm{C},>95 \%\right.$ relative humidity) for at least 1 hour. To measure the setting time, the needle of a custom-made Vicat apparatus was adjusted vertically onto the surface of the sealer. The setting time was determined as the time when the indenter needle failed to create an indentation. The measurement interval was adjusted from 1 hour at the beginning to $5 \mathrm{~min}$ in accordance with the setting process. The time from the onset 
TABLE 2: Chemical compositions of the root canal sealers investigated in the present study.

\begin{tabular}{|c|c|c|c|}
\hline \multicolumn{2}{|l|}{ Sealer } & \multicolumn{2}{|c|}{ Components } \\
\hline \multirow{6}{*}{ Epoxy resin-based sealer } & \multirow[b]{2}{*}{ Radic-Sealer } & Base & Catalyst \\
\hline & & $\begin{array}{l}\text { Poly epoxy resin } \\
\text { Zirconium oxide }\end{array}$ & $\begin{array}{l}\text { TEA (triethanolamine) } \\
\text { Zirconium oxide } \\
\text { Calcium oxide }\end{array}$ \\
\hline & & Base & Catalyst \\
\hline & AD Seal & $\begin{array}{c}<20 \% \text { epoxy resin } \\
\text { NS calcium phosphate } \\
\text { NS zirconium dioxide } \\
\text { NS calcium oxide } \\
\text { NS ethylene glycol salicylate }\end{array}$ & $\begin{array}{c}2.5 \%-10 \% \mathrm{~N} \\
\text { n-dibenzyl-5-oxanonandiamin-1,9 } \\
2.5 \%-10 \% \text { amantadine }\end{array}$ \\
\hline & & Paste A & Paste B \\
\hline & AH-Plus & $\begin{array}{c}25 \%-50 \% \text { bisphenol A } \\
10 \%-25 \% \text { zirconium dioxide } \\
\text { NS calcium tungstate } \\
\text { NS iron oxide }\end{array}$ & $\begin{array}{c}2.5 \%-10 \% \mathrm{~N} \\
\text { n-dibenzyl-5-oxanonandiamin-1,9 } \\
2.5 \%-10 \% \text { amantadine }\end{array}$ \\
\hline \multirow{3}{*}{ Bioceramic-based sealer } & EndoSequence BC Sealer & \multicolumn{2}{|c|}{$\begin{array}{c}\text { Zirconium oxide, calcium silicates, calcium phosphate monobasic, calcium } \\
\text { hydroxide, filler, thickening agents }\end{array}$} \\
\hline & EndoSeal MTA & \multicolumn{2}{|c|}{$\begin{array}{l}\text { Calcium silicates, calcium aluminates, calcium aluminoferrite, calcium sulfates, } \\
\text { radiopacifier, thickening agents }\end{array}$} \\
\hline & MTA Fillapex & \multicolumn{2}{|c|}{$\begin{array}{l}\text { Salicylate resin, diluting resin, natural resin, bismuth trioxide, nanoparticulated } \\
\text { silica, MTA }\end{array}$} \\
\hline
\end{tabular}

of mixing to the sealer setting was taken as the setting time. Ten measurements were made for each sealer.

2.3. Radiopacity. Ten cylindrical samples were fabricated from each sealer by placing the handled sealers into metallic rings with $8 \mathrm{~mm}$ internal diameter and $1 \mathrm{~mm}$ thickness. Then the filled rings were stored at $37^{\circ} \mathrm{C}$ until sealers were completely set. The samples were radiographed on a digital $\mathrm{X}$-ray sensor (Schick Technology Inc., Long Island City, $\mathrm{NY}$ ) with an aluminum step-wedge graduated from $1 \mathrm{~mm}$ to $10 \mathrm{~mm}$ (in $1 \mathrm{~mm}$ increment), which was used with exposures set at $60 \mathrm{kV}, 2 \mathrm{~mA}, 0.08$ seconds, and a focus-film distance of $10 \mathrm{~cm}$. The aluminum wedge equivalent thickness ( $\mathrm{mm} \mathrm{Al}$ ) of each sealer was analyzed by using Photoshop (Adobe photo shop 7.0; Adobe systems Incorporated, San Jose, CA).

2.4. Dimensional Stability. Dimensional stability was measured for the settable sealers of 3 epoxy resin-based sealers and EndoSeal MTA. Cylindrical Teflon molds (inner diameter $6 \mathrm{~mm}$, height $12 \mathrm{~mm}$ ) were filled with mixed sealer and backed by a glass plate on each side. The whole assembly was transferred to an incubator and kept for at least 3 times the measured setting time. After deciding the complete setting, the ends of the molds containing the specimens were ground by using 600-grit sandpaper with water supply. Then the specimens were removed from the mold and measured for length $\left(L_{0}\right)$ using a digital caliper with a resolution of $0.01 \mathrm{~mm}$. The specimens were stored in distilled water and kept in an incubator throughout the study period $(6,24$, and 72 hours and 7, 14, and 30 days). After being immersed in water for the assigned periods, the dimensions of 4 tested sealers were compared to their initial dimension. The samples were then blotted dry with tissue paper and measured again for length $\left(L_{1}\right)$. The test was implemented ten times for each sealer, and the change in length was recorded as the dimensional change $(D)$ using the following formula: $D(\%)=$ $\left(L_{1}-L_{0}\right) / L_{0} \times 100$.

2.5. $p H$ Change. The sealer samples mixed immediately after manipulation were denoted as fresh samples, and the samples stored in the incubator until setting were denoted as set samples. Teflon molds (inner diameter $5 \mathrm{~mm}$, thickness $1 \mathrm{~mm}$ ) were used to shape the set samples. Both the set sample and fresh sample were dropped in distilled water in a polypropylene conical tube and then stored at $37^{\circ} \mathrm{C}$ throughout the study period. After predetermined periods ( 3 , 30 , and 60 minutes and 2, 12, and 24 hours for fresh samples and 12 hours, 3 days, 7 days, 2 weeks, and 4 weeks for set samples), the $\mathrm{pH}$ of the solution was measured by using a digital pH meter (STARTER 2100 Bench pH Meter; Ohaus). Ten measurements were made for each sealer and condition.

2.6. Statistical Analysis. The one-way ANOVA test and Tukey's post hoc test were used to compare the physicochemical property results by using SPSS software 10.0 (SPSS Inc., Chicago, IL). The significance level was set at $P<0.05$.

\section{Results}

The physical properties of the sealers are summarized in Table 3.

All the tested sealers except BC Sealer showed the flow greater than $20 \mathrm{~mm}$, which is in agreement with the ISO standards [13]. MTA Fillapex had a highest flow and BC 
TABLE 3: The flow (mm), setting time ( $\mathrm{min})$, and radiopacity (mmAl thickness) of tested sealers (mean \pm standard deviation).

\begin{tabular}{|c|c|c|c|c|c|c|}
\hline & Radic-Sealer & AD Seal & AH-Plus & $\begin{array}{c}\text { EndoSequence } \\
\text { BC Sealer }\end{array}$ & EndoSeal MTA & MTA Fillapex \\
\hline $\begin{array}{l}\text { Flow } \\
(\mathrm{mm})\end{array}$ & $20.80 \pm 0.84^{\mathrm{b}}$ & $21.87 \pm 1.40^{\mathrm{b}}$ & $21.87 \pm 1.40^{\mathrm{b}}$ & $18.45 \pm 1.31^{\mathrm{c}}$ & $20.21 \pm 1.57^{\mathrm{b}}$ & $34.13 \pm 2.91^{\mathrm{a}}$ \\
\hline $\begin{array}{l}\text { Setting time } \\
\text { (min) }\end{array}$ & $114.1 \pm 2.8^{\mathrm{c}}$ & $115.7 \pm 2.8^{\mathrm{c}}$ & $959.6 \pm 79.0^{\mathrm{b}}$ & - & $1223.4 \pm 156.3^{\mathrm{a}}$ & - \\
\hline $\begin{array}{l}\text { Radiopacity } \\
\text { (mmAl) }\end{array}$ & $7.67 \pm 0.38^{\mathrm{b}}$ & $4.70 \pm 0.33^{\mathrm{d}}$ & $10.00^{\mathrm{a} *}$ & $6.68 \pm 0.99^{c}$ & $9.50 \pm 0.84^{\mathrm{a}}$ & $3.01 \pm 0.20^{\mathrm{e}}$ \\
\hline
\end{tabular}

a,b,c,d,e Different letters in each line indicate significant difference $(P<0.05)$.

* All of the AH plus samples had $10 \mathrm{mmAl}$ thickness or the higher values.

TABLE 4: The dimensional stability (\%) of the tested sealers at various time periods (mean \pm standard deviation).

\begin{tabular}{lcccccc}
\hline Ratio (\%) & 6 hours & 24 hours & 72 hours & 7 days & 14 days & 30 days \\
\hline Radic-Sealer & $0.42 \pm 0.33^{\mathrm{AB}}$ & $0.62 \pm 0.35^{\mathrm{aBC}}$ & $0.98 \pm 0.28^{\mathrm{aC}}$ & $1.73 \pm 0.39^{\mathrm{aD}}$ & $2.22 \pm 0.28^{\mathrm{bDE}}$ & $2.69 \pm 0.32^{\mathrm{bE}}$ \\
AD Seal & $0.21 \pm 0.27^{\mathrm{A}}$ & $0.55 \pm 0.32^{\mathrm{aAB}}$ & $1.20 \pm 0.39^{\mathrm{aB}}$ & $2.07 \pm 0.56^{\mathrm{aC}}$ & $2.88 \pm 0.54^{\mathrm{aD}}$ & $3.41 \pm 0.76^{\mathrm{aD}}$ \\
AH-Plus & $0.10 \pm 0.64$ & $0.13 \pm 0.65^{\mathrm{b}}$ & $0.23 \pm 0.55^{\mathrm{b}}$ & $0.24 \pm 0.64^{\mathrm{b}}$ & $0.25 \pm 0.54^{\mathrm{c}}$ & $0.35 \pm 0.51^{\mathrm{c}}$ \\
EndoSeal MTA & $0.36 \pm 0.32$ & $0.33 \pm 0.28^{\mathrm{ab}}$ & $0.25 \pm 0.34^{\mathrm{b}}$ & $0.14 \pm 0.33^{\mathrm{b}}$ & $0.23 \pm 0.29^{\mathrm{c}}$ & $0.21 \pm 0.31^{\mathrm{c}}$ \\
\hline
\end{tabular}

${ }_{\mathrm{a}, \mathrm{b}, \mathrm{c}}$ Different letters in each column indicate significant difference between groups at the same period $(P<0.05)$.

$\mathrm{A}, \mathrm{B}, \mathrm{C}, \mathrm{D}, \mathrm{E}$ Different capital letters indicate significant difference during the time periods in the same material $(P<0.05)$.

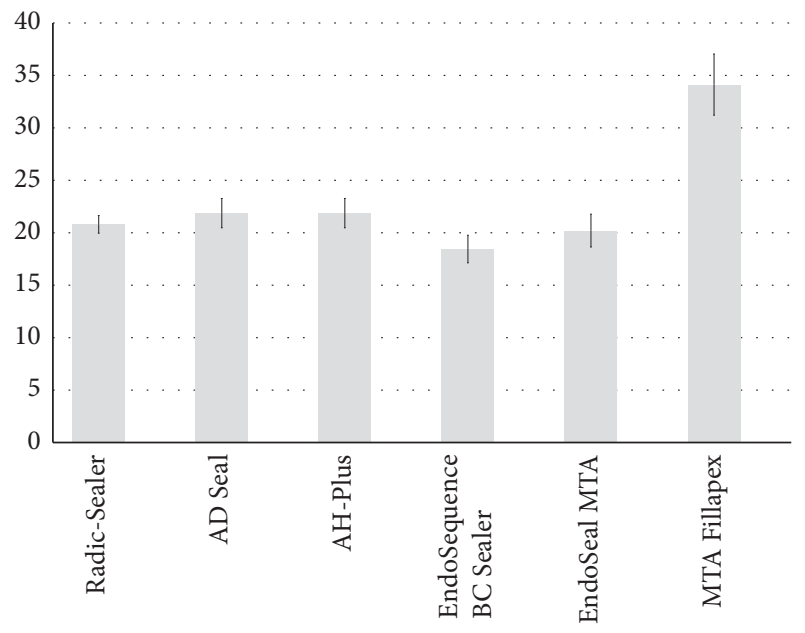

FIgURE 2: Flow values from each sealer evaluated (in $\mathrm{mm}$ ). ${ }^{a, b, c}$ Different letters present significant difference between groups $(P<0.05)$.

Sealer presented a significantly lower flow than the other sealers $(P<0.05)$ (Figure 2$)$.

BC Sealer and MTA Fillapex were not set in humid incubator condition even after one month. EndoSeal MTA had the longest setting time (mean: $1223 \mathrm{~min}$ ) among the measurable materials and Radic-Sealer and AD Seal showed shorter setting time than the AH-Plus $(P<0.05)$.

For the radiopacity test, AH-Plus and EndoSeal MTA showed statistically higher values and MTA Fillapex showed statistically lower values in comparison to the other evaluated sealers $(P<0.05)$ (Figure 3$)$. All the tested sealers showed radiopacity values complying with the ISO standards [13].

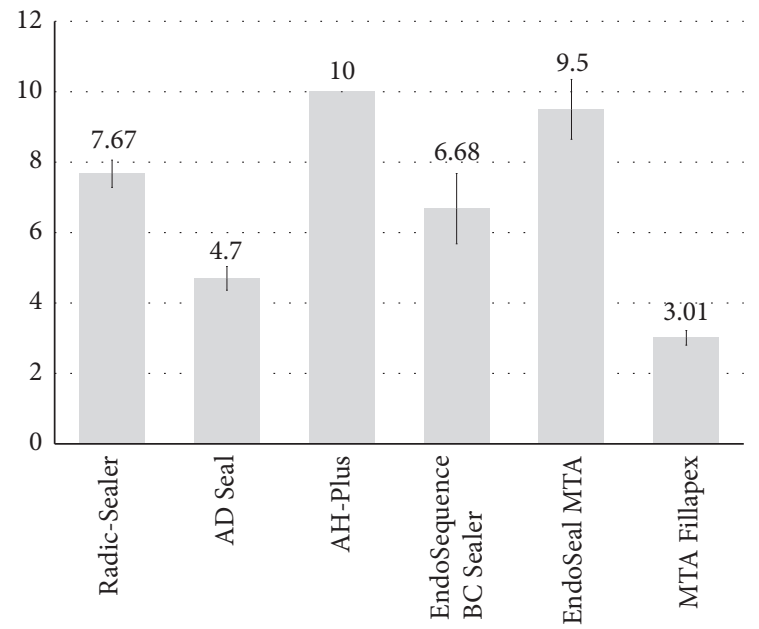

FIGURE 3: Radiopacity values from each sealer evaluated (in $\mathrm{mm} \mathrm{Al}$ ). $\mathrm{a}, \mathrm{b}, \mathrm{c}, \mathrm{d}, \mathrm{e}$ Different letters present significant difference between groups $(P<0.05)$.

Dimensional stability was measured for the settable sealers of 3 epoxy resin-based sealers and EndoSeal MTA. After being immersed in water for 30 days, 4 tested sealers expanded compared to their initial dimension. At 30 days, AD Seal had a significantly greater expansion than the others $(P<0.05)$ (Table 4, Figure 4).

Fresh samples of the tested sealers showed significant differences of $\mathrm{pH}$ change among themselves at all evaluation time points and $\mathrm{BC}$ Sealer showed the highest alkaline $\mathrm{pH}$ in all evaluation periods (Table 5, Figure 5). Set samples of 3 epoxy resin-based sealers and EndoSeal MTA presented a significant increase of $\mathrm{pH}$ over experimental time for 4 weeks. 
TABLE 5: pH change of freshly mixed samples during 24 hours.

\begin{tabular}{lcccccc}
\hline & $3 \min$ & $30 \min$ & $60 \min$ & 2 hours & 12 hours & 24 hours \\
\hline Radic-Sealer & $8.84 \pm 0.25^{\mathrm{d}}$ & $8.59 \pm 0.27^{\mathrm{e}}$ & $8.34 \pm 0.13^{\mathrm{e}}$ & $7.77 \pm 0.34^{\mathrm{e}}$ & $7.72 \pm 0.17^{\mathrm{e}}$ & $7.70 \pm 0.26^{\mathrm{e}}$ \\
AD Seal & $9.06 \pm 0.47^{\mathrm{d}}$ & $8.91 \pm 0.55^{\mathrm{d}}$ & $8.65 \pm 0.67^{\mathrm{d}}$ & $8.41 \pm 0.92^{\mathrm{d}}$ & $7.87 \pm 0.68^{\mathrm{e}}$ & $7.46 \pm 0.77^{\mathrm{e}}$ \\
AH-Plus & $9.33 \pm 0.28^{\mathrm{c}}$ & $9.45 \pm 0.26^{\mathrm{c}}$ & $9.37 \pm 0.23^{\mathrm{c}}$ & $9.18 \pm 0.37^{\mathrm{c}}$ & $8.91 \pm 0.46^{\mathrm{d}}$ & $8.68 \pm 0.60^{\mathrm{d}}$ \\
BC Sealer & $11.64 \pm 0.03^{\mathrm{a}}$ & $11.60 \pm 0.02^{\mathrm{a}}$ & $11.67 \pm 0.03^{\mathrm{a}}$ & $11.7 \pm 0.03^{\mathrm{a}}$ & $11.78 \pm 0.03^{\mathrm{a}}$ & $11.78 \pm 0.03^{\mathrm{a}}$ \\
EndoSeal MTA & $10.41 \pm 0.05^{\mathrm{b}}$ & $10.42 \pm 0.06^{\mathrm{b}}$ & $10.42 \pm 0.07^{\mathrm{b}}$ & $10.45 \pm 0.07^{\mathrm{b}}$ & $10.77 \pm 0.06^{\mathrm{b}}$ & $10.90 \pm 0.05^{\mathrm{b}}$ \\
MTA Fillapex & $8.50 \pm 0.26^{\mathrm{e}}$ & $8.93 \pm 0.13^{\mathrm{d}}$ & $9.30 \pm 0.15^{\mathrm{c}}$ & $9.52 \pm 0.18^{\mathrm{c}}$ & $9.90 \pm 0.11^{\mathrm{c}}$ & $10.02 \pm 0.23^{\mathrm{c}}$ \\
\hline
\end{tabular}

$\overline{\mathrm{a}, \mathrm{b}, \mathrm{c}, \mathrm{d}, \mathrm{e}}$ Different letters in each column indicate significant difference between sealer groups at the tested period $(P<0.05)$.

TABLE 6: pH change of set samples during 4 weeks.

\begin{tabular}{lcccccc}
\hline & Initial & 12 hours & 3 days & 7 days & 2 weeks & 4 weeks \\
\hline Radic-Sealer & $5.79 \pm 0.06$ & $6.35 \pm 0.09^{\mathrm{c}}$ & $6.51 \pm 0.12^{\mathrm{c}}$ & $6.40 \pm 0.13^{\mathrm{c}}$ & $6.59 \pm 0.51^{\mathrm{d}}$ & $6.34 \pm 0.39^{\mathrm{c}}$ \\
AD Seal & $5.84 \pm 0.57$ & $6.95 \pm 0.83^{\mathrm{b}}$ & $7.30 \pm 0.75^{\mathrm{b}}$ & $7.15 \pm 0.74^{\mathrm{b}}$ & $7.51 \pm 0.86^{\mathrm{c}}$ & $7.49 \pm 0.74^{\mathrm{b}}$ \\
AH-Plus & $5.84 \pm 0.04$ & $5.85 \pm 0.35^{\mathrm{d}}$ & $5.87 \pm 0.47^{\mathrm{d}}$ & $5.96 \pm 0.44^{\mathrm{d}}$ & $6.10 \pm 0.94^{\mathrm{b}}$ & $6.40 \pm 0.47^{\mathrm{c}}$ \\
EndoSeal MTA & $5.76 \pm 0.11$ & $10.58 \pm 0.06^{\mathrm{a}}$ & $10.90 \pm 0.05^{\mathrm{a}}$ & $11.02 \pm 0.04^{\mathrm{a}}$ & $11.26 \pm 0.04^{\mathrm{a}}$ & $11.29 \pm 0.07^{\mathrm{a}}$ \\
\hline
\end{tabular}

$\overline{\mathrm{a}, \mathrm{b}, \mathrm{c}, \mathrm{d}}$ Different letters in each column indicate significant difference between sealers at the tested period $(P<0.05)$.

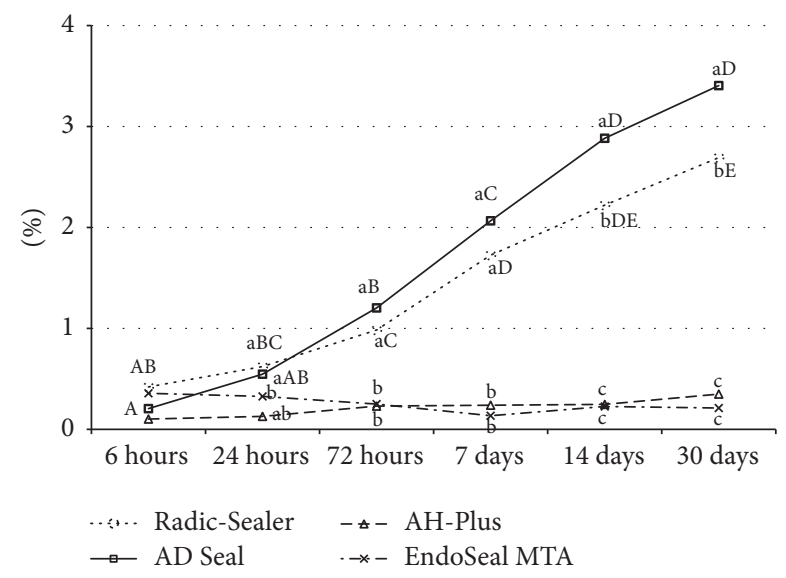

Figure 4: Dimensional stability (\%) of the test sealers at various time periods. Different letters present significant differences between groups $(\mathrm{a}, \mathrm{b}$, and $\mathrm{c})$ at the same period and between the time periods $(\mathrm{A}, \mathrm{B}, \mathrm{C}, \mathrm{D}$, and $\mathrm{E})$ in the same material $(P<0.05)$.

The $\mathrm{pH}$ of EndoSeal MTA was significantly higher than that of 3 epoxy resin-based root canal sealers at all experimental time points. Radic-Sealer and AH-Plus showed mild acidity around $\mathrm{pH} 6$ and $\mathrm{AD}$ Seal presented neutral $\mathrm{pH}$ at 4 weeks $(P<0.05)$ (Table 6, Figure 6).

\section{Discussion}

Among the clinically available root canal sealers, epoxy resinbased sealers are widely used for root canal filling due to their resorption resistance and dimensional stability [4-6]. Most recently introduced bioceramic-based materials have attractive physical, chemical, mechanical, and biological properties $[10,11,17]$. Therefore, the representative 3 epoxy resin-based

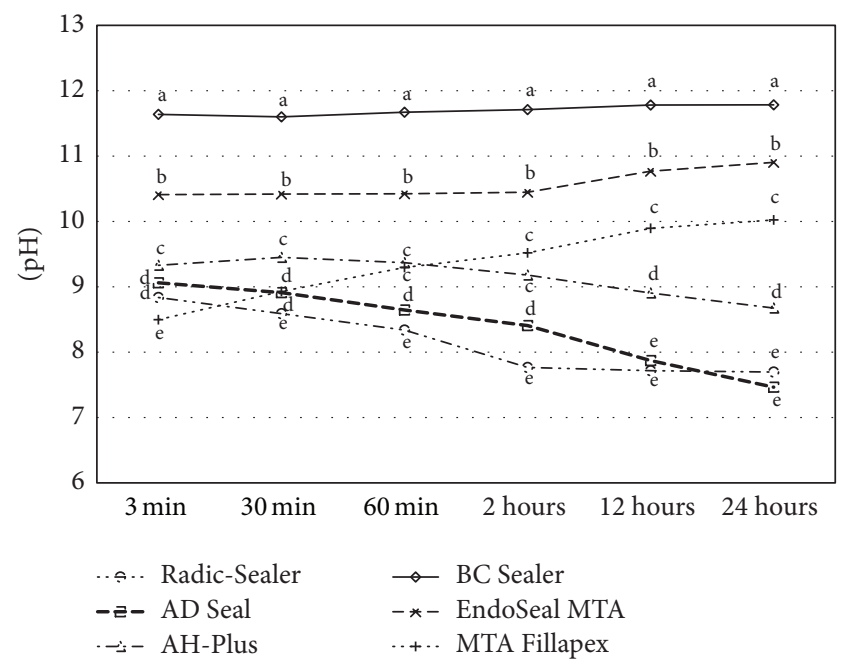

FIGURE 5: pH change of freshly mixed samples during 24 hours. $\mathrm{a}, \mathrm{b}, \mathrm{c}, \mathrm{d}, \mathrm{e}$ Different letters present significant difference between sealers at the tested period $(P<0.05)$.

sealers and 3 bioceramic-based sealers were compared for physical and chemical properties, in this study.

The flow of endodontic sealers may have an effect on obturation of accessory canals and microspaces between master and accessory cones [3]. Various factors such as composition, shear rate, particle size, temperature, and time from mixing are related to the flowability of sealers [3]. MTA Fillapex sealer had the highest flow and BC Sealer presented the lowest flow in this study. The flow value of MTA Fillapex was similar to the value obtained by Silva et al. [18]. A high resin/MTA ratio may be one of the reasons why a high flow rate occurs [19]. 


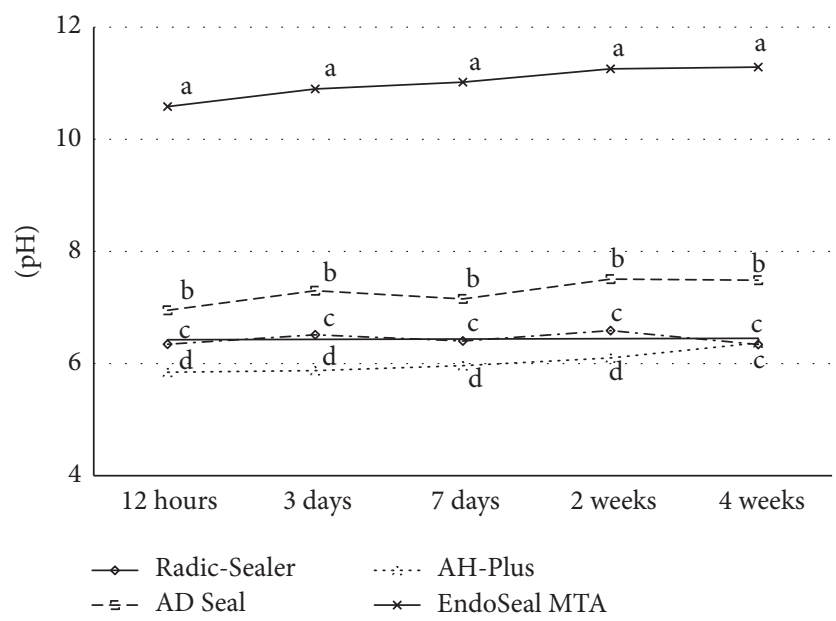

FIgURE 6: pH change of set samples during 4 weeks. ${ }^{\mathrm{a}, \mathrm{b}, \mathrm{c}, \mathrm{d}}$ Different letters present significant difference between four sealers at the same test time periods $(P<0.05)$.

Setting time is also important to provide adequate working time and proper consistency enough to fill the root canal system completely [20]. Setting times of evaluated sealers in this study were different from that given by the manufacture. Only AH-Plus was in agreement with the ISO standards and it showed a significant higher mean setting time value, almost 8 times greater than the other epoxy resin-based root canal sealers. AH-Plus is comprised of base and catalyst in which a slow polymerization reaction of epoxy resin amines with a high molecular weight including bisphenol A and bisphenol F occurs [21]. This chemical composition could explain significantly higher setting time of it. On the other hand, Radic-Sealer and AD Seal are the kind of resin composites containing a catalyst component that accelerates the process [22]. In the meanwhile, BC Sealer and MTA Fillapex were not set in humid incubator condition, and this result was different from several reports that final setting of these materials occurred [4-6, 10, 23, 24]. Depending on Loushine et al. [10], water is essential for this sealer to reach its final set because the inorganic and radiopacifier components of the sealer are premixed with water-free liquid-thickening carriers, and the manufacturer suggests that there is a prolonged setting time in overly dry canals. However, the authors concluded that overly wet canals may affect the setting time and, in particular, adversely affect the microhardness of the sealer after setting [10]. They also pointed out that a more porous matrix would be present when the sealer sets in the wet canals, which, in turn, may result in increased leaching of tissue-irritating substances from the sealer [10]. The delayed setting time of sealers may also affect biocompatibility and the sealers may have the potential to release cytotoxic byproducts before the final setting [10]. Silva et al. [18] reported that MTA Fillapex showed severe cytotoxicity when cells were exposed to the fresh sealer and the toxicity was not decreased over the tested time periods. These findings are in agreement with other previous studies $[25,26]$ that showed strongly affected cell viability with MTA Fillapex.
Radiopacity is an essential property of endodontic sealing materials. Among other physical, chemical, and biological properties, the ideal root canal sealing material should have a certain level of radiopacity [27]. Sufficient radiopacity allows clinicians to make a clear distinction between the materials and the surrounding anatomic structures and to evaluate the quality of the root fillings [28]. International standards require a minimal radiopacity equivalent to $3.00 \mathrm{mmAl}$ [29]. In the present study, AH-Plus and EndoSeal MTA showed statistically higher radiopacity values $(P<0.05)$, but all the tested sealers exhibited values complying with the international standards. Vitti et al. [19] suggested that the differences between radiopacities of root canal sealers probably were caused by the presence of different radiopacifying agents in each material. According to Duarte et al. [30], radiopacity of AH-Plus is provided by zirconium oxide and calcium tungstate and suggested that its radiopacity could vary in different published studies because of the deposition of radiopacifying agents at the lower end of the tube, whereas the upper portion can present a lower quantity of its substance [19].

In this study, 4 tested sealers expanded compared to initial dimension and AD Seal had a significant increase of height (i.e., expansion) than the others. This increase of mass and height presented by 3 epoxy resin-based sealers probably occurred as a result of the water absorption and a high expansion of resin-based sealers, which was also verified by Versiani et al. [31]. AH-Plus maintained the most constant mass, presenting mass change rate within $-0.5 \%$ (minus value means water sorption) for 30 days in this study. Dimensional change values ranging from $0.62 \%$ to $1.28 \%$ for $\mathrm{AH}$-Plus obtained in previous investigations were also explained by water sorption after polymerization [31, 32]. It has been demonstrated that polymerized materials from mixtures of hydrophilic monomers had high water sorption [33]. And the dimensional change of EndoSeal MTA was not significant with the minimal change of specimens' height in this study. However, all the tested materials showed bigger expansion rate than the favorable rate suggested by the international standards (Table 1). Therefore, it is highly recommended to study the potential risk of inducing the vertical root fractures by the sealer expansion.

An alkaline $\mathrm{pH}$ may contribute to their osteogenic potential, biocompatibility, and antibacterial ability [3, 3437]. It has been reported that an alkaline $\mathrm{pH}$ of root canal sealers could neutralize the lactic acid from osteoclasts and prevent dissolution of mineralized components of teeth. Therefore, root canal sealers can contribute to hard tissue formation by activating alkaline phosphatase [38]. In this study, the $\mathrm{pH}$ value of 3 freshly prepared bioceramic-based root canal sealers remained significantly higher than that of 3 epoxy resin-based sealers for 24 hours, with the highest alkaline $\mathrm{pH}$ measured from $\mathrm{BC}$ Sealer for the entire period of evaluation. Considering the setting time required, BC Sealer with prolonged high $\mathrm{pH}$ (up to 12) before its setting may cause damage to the periapical tissue via the loss of cell viability and membrane integrity, similar to cellular responses observed in chemical burns. Such complications thus need to be carefully considered, along with bactericidal effect of the sealers. In 
case of set samples, the $\mathrm{pH}$ of EndoSeal MTA was significantly higher than that of 3 epoxy resin-based root canal sealers at all experimental time points $(P<0.05)$.

\section{Conclusion}

Based on the present results, the tested epoxy resin-based sealers as well as the bioceramic-based sealers except the BC Sealer and MTA Fillapex are showed to fulfill the required chemical and physical properties as ideal root canal sealers. The EndoSequence BC Sealer and MTA Fillapex should be improved to be set finally within clinically acceptable time limit. Clinical trial tests and long term follow-up studies using various types of the sealers would be highly valuable to evaluate the sealers' clinical performances.

\section{Competing Interests}

The authors deny any conflict of interests related to this study.

\section{Authors' Contributions}

Ju Kyung Lee and Sang Won Kwak contributed equally to this work and share the first authorship.

\section{References}

[1] J. Branstetter and J. A. von Fraunhofer, "The physical properties and sealing action of endodontic sealer cements: a review of the literature," Journal of Endodontics, vol. 8, no. 7, pp. 312-316, 1982.

[2] L. I. Grossman, Endodontic Practice, Henry Kimpton, Philadelphia, Pa, USA, 10th edition, 1981.

[3] H. M. Zhou, Y. Shen, W. Zheng, L. Li, Y. F. Zheng, and M. Haapasalo, "Physical properties of 5 root canal sealers," Journal of Endodontics, vol. 39, no. 10, pp. 1281-1286, 2013.

[4] A. D. B. Garrido, R. C. C. Lia, S. C. França, J. F. da Silva, S. Astolfi-Filho, and M. D. Sousa-Neto, "Laboratory evaluation of the physicochemical properties of a new root canal sealer based on Copaifera multijuga oil-resin," International Endodontic Journal, vol. 43, no. 4, pp. 283-291, 2010.

[5] C. Tennert, I. L. Jungbäck, and K.-T. Wrbas, "Comparison between two thermoplastic root canal obturation techniques regarding extrusion of root canal filling - a retrospective in vivo study," Clinical Oral Investigations, vol. 17, no. 2, pp. 449-454, 2013.

[6] M. Wolf, K. Küpper, S. Reimann, C. Bourauel, and M. Frentzen, "3D analyses of interface voids in root canals filled with different sealer materials in combination with warm guttapercha technique," Clinical Oral Investigations, vol. 18, no. 1, pp. 155-161, 2014.

[7] A. Schroeder, Endodontics: Science and Practice-A Textbook for Student and Practitioner, Quintessence, Chicago, Ill, USA, 1981.

[8] M. Torabinejad, J. D. Kettering, and L. K. Bakland, "Evaluation of systemic immunological reactions to $\mathrm{AH}-26$ root canal sealer," Journal of Endodontics, vol. 5, no. 7, pp. 196-200, 1979.

[9] A. Wennberg, "Biological evaluation of root canal sealers using in vitro and in vivo methods," Journal of Endodontics, vol. 6, no. 10, pp. 784-787, 1980.

[10] B. A. Loushine, T. E. Bryan, S. W. Looney et al., "Setting properties and cytotoxicity evaluation of a premixed bioceramic root canal sealer," Journal of Endodontics, vol. 37, no. 5, pp. 673677, 2011.

[11] E.-S. Lim, Y.-B. Park, Y.-S. Kwon, W.-J. Shon, K.-W. Lee, and K.-S. Min, "Physical properties and biocompatibility of an injectable calcium-silicate-based root canal sealer: in vitro and in vivo study," BMC Oral Health, vol. 15, article 129, 2015.

[12] International Organization for Standardization, "Dental root canal sealing materials," ISO 6876, International Organization for Standardization, Geneva, Switzerland, 2001.

[13] American National Standards/American Dental Association, Endodontic Sealing Material, ANSI/ADA Specification no. 57, American National Standards/American Dental Association, Chicago, Ill, USA, 2000.

[14] H. Zhang, Y. Shen, N. D. Ruse, and M. Haapasalo, "Antibacterial activity of endodontic sealers by modified direct contact test against enterococcus faecalis," Journal of Endodontics, vol. 35, no. 7, pp. 1051-1055, 2009.

[15] Y. Song, Y. Choi, M. Lim et al., "In vitro evaluation of a newly produced resin-based endodontic sealer," Restorative Dentistry é Endodontics, vol. 41, no. 3, pp. 189-195, 2016.

[16] T. Tașdemir, C. Yesilyurt, T. Yildirim, and K. Er, "Evaluation of the radiopacity of new root canal paste/sealers by digital radiography," Journal of Endodontics, vol. 34, no. 11, pp. 13881390, 2008

[17] G. T. D. M. Candeiro, F. C. Correia, M. A. H. Duarte, D. C. Ribeiro-Siqueira, and G. Gavini, "Evaluation of radiopacity, $\mathrm{pH}$, release of calcium ions, and flow of a bioceramic root canal sealer," Journal of Endodontics, vol. 38, no. 6, pp. 842-845, 2012.

[18] E. J. N. L. Silva, T. P. Rosa, D. R. Herrera, R. C. Jacinto, B. P. F. A. Gomes, and A. A. Zaia, "Evaluation of cytotoxicity and physicochemical properties of calcium silicate-based endodontic sealer MTA Fillapex," Journal of Endodontics, vol. 39, no. 2, pp. 274277, 2013.

[19] R. P. Vitti, C. Prati, E. J. N. L. Silva et al., "Physical properties of MTA fillapex sealer," Journal of Endodontics, vol. 39, no. 7, pp. 915-918, 2013.

[20] A. Donnelly, J. Sword, Y. Nishitani et al., "Water sorption and solubility of methacrylate resin-based root canal sealers," Journal of Endodontics, vol. 33, no. 8, pp. 990-994, 2007.

[21] L. M. Resende, F. J. A. Rached-Junior, M. A. Versiani et al., "A comparative study of physicochemical properties of AH plus, epiphany, and epiphany SE root canal sealers," International Endodontic Journal, vol. 42, no. 9, pp. 785-793, 2009.

[22] M. Pawińska, A. Kierklo, and G. Marczuk-Kolada, "New technology in endodontics-the resilon-epiphany system for obturation of root canals," Advances in medical sciences, vol. 51, no. 1, pp. 154-157, 2006.

[23] D. H. Pashley, "Dynamics of the pulpo-dentin complex," Critical Reviews in Oral Biology and Medicine, vol. 7, no. 2, pp. 104-133, 1996.

[24] J. D. Pecora, A. Brugnera Jr., A. L. Cussioli, F. Zanin, and R. Silva, "Evaluation of dentin root canal permeability after instrumentation and Er:YAG laser application," Lasers in Surgery and Medicine, vol. 26, no. 3, pp. 277-281, 2000.

[25] C. V. Bin, M. C. Valera, S. E. A. Camargo et al., "Cytotoxicity and genotoxicity of root canal sealers based on mineral trioxide aggregate," Journal of Endodontics, vol. 38, no. 4, pp. 495-500, 2012.

[26] M. Z. Scelza, A. B. Linhares, L. E. Da Silva, J. M. Granjeiro, and G. G. Alves, "A multiparametric assay to compare the cytotoxicity of endodontic sealers with primary human osteoblasts," International Endodontic Journal, vol. 45, no. 1, pp. 12-18, 2012. 
[27] B. G. Baksi (Akdeniz), T. F. Eyüboĝlu, B. H. Şen, and N. Erdilek, "The effect of three different sealers on the radiopacity of root fillings in simulated canals," Oral Surgery, Oral Medicine, Oral Pathology, Oral Radiology, and Endodontics, vol. 103, no. 1, pp. 138-141, 2007.

[28] G. A. Marín-Bauza, Y. T. C. Silva-Sousa, S. A. da Cunha et al., "Physicochemical properties of endodontic sealers of different bases," Journal of Applied Oral Science, vol. 20, no. 4, pp. 455461, 2012.

[29] M. Tagger and A. Katz, "Radiopacity of endodontic sealers: development of a new method for direct measurement," Journal of Endodontics, vol. 29, no. 11, pp. 751-755, 2003.

[30] M. A. H. Duarte, R. Ordinola-Zapata, R. A. Bernardes et al., "Influence of calcium hydroxide association on the physical properties of AH plus," Journal of Endodontics, vol. 36, no. 6, pp. 1048-1051, 2010.

[31] M. A. Versiani, J. R. Carvalho Jr., M. I. A. F. Padilha, S. Lacey, E. A. Pascon, and M. D. Sousa-Neto, "A comparative study of physicochemical properties of AH Plus ${ }^{\mathrm{TM}}$ and Epiphany ${ }^{\mathrm{TM}}$ root canal sealants," International Endodontic Journal, vol. 39, no. 6, pp. 464-471, 2006.

[32] J. R. Carvalho-Junior, L. Correr-Sobrinho, A. B. Correr, M. A. C. Sinhoreti, S. Consani, and M. D. Sousa-Neto, "Solubility and dimensional change after setting of root canal sealers: a proposal for smaller dimensions of test samples," Journal of Endodontics, vol. 33, no. 9, pp. 1110-1116, 2007.

[33] M. Braden and R. L. Clarke, "Water absorption characteristics of dental microfine composite filling materials: I. Proprietary materials," Biomaterials, vol. 5, no. 6, pp. 369-372, 1984.

[34] C. P. McHugh, P. Zhang, S. Michalek, and P. D. Eleazer, "pH required to kill Enterococcus faecalis in vitro," Journal of Endodontics, vol. 30, no. 4, pp. 218-219, 2004.

[35] T. Okabe, M. Sakamoto, H. Takeuchi, and K. Matsushima, "Effects of $\mathrm{pH}$ on mineralization ability of human dental pulp cells," Journal of Endodontics, vol. 32, no. 3, pp. 198-201, 2006.

[36] C. H. Stuart, S. A. Schwartz, T. J. Beeson, and C. B. Owatz, "Enterococcus faecalis: its role in root canal treatment failure and current concepts in retreatment," Journal of Endodontics, vol. 32, no. 2, pp. 93-98, 2006.

[37] S. Desai and N. Chandler, "Calcium hydroxide-based root canal sealers: a review," Journal of Endodontics, vol. 35, no. 4, pp. 475480, 2009.

[38] C. J. Stock, "Calcium hydroxide: root resorption and perio-endo lesions," British Dental Journal, vol. 158, no. 9, pp. 325-334, 1985. 

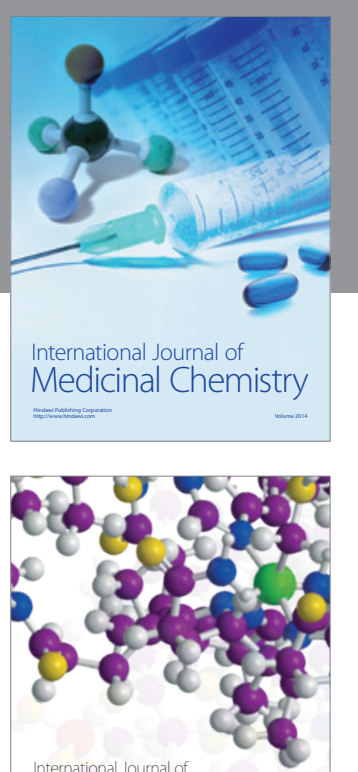

Carbohydrate Chemistry

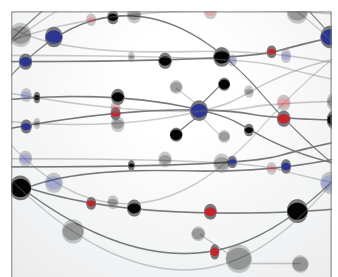

The Scientific World Journal
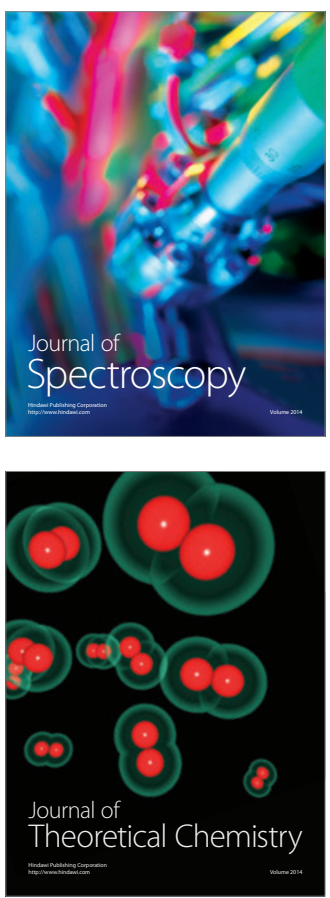
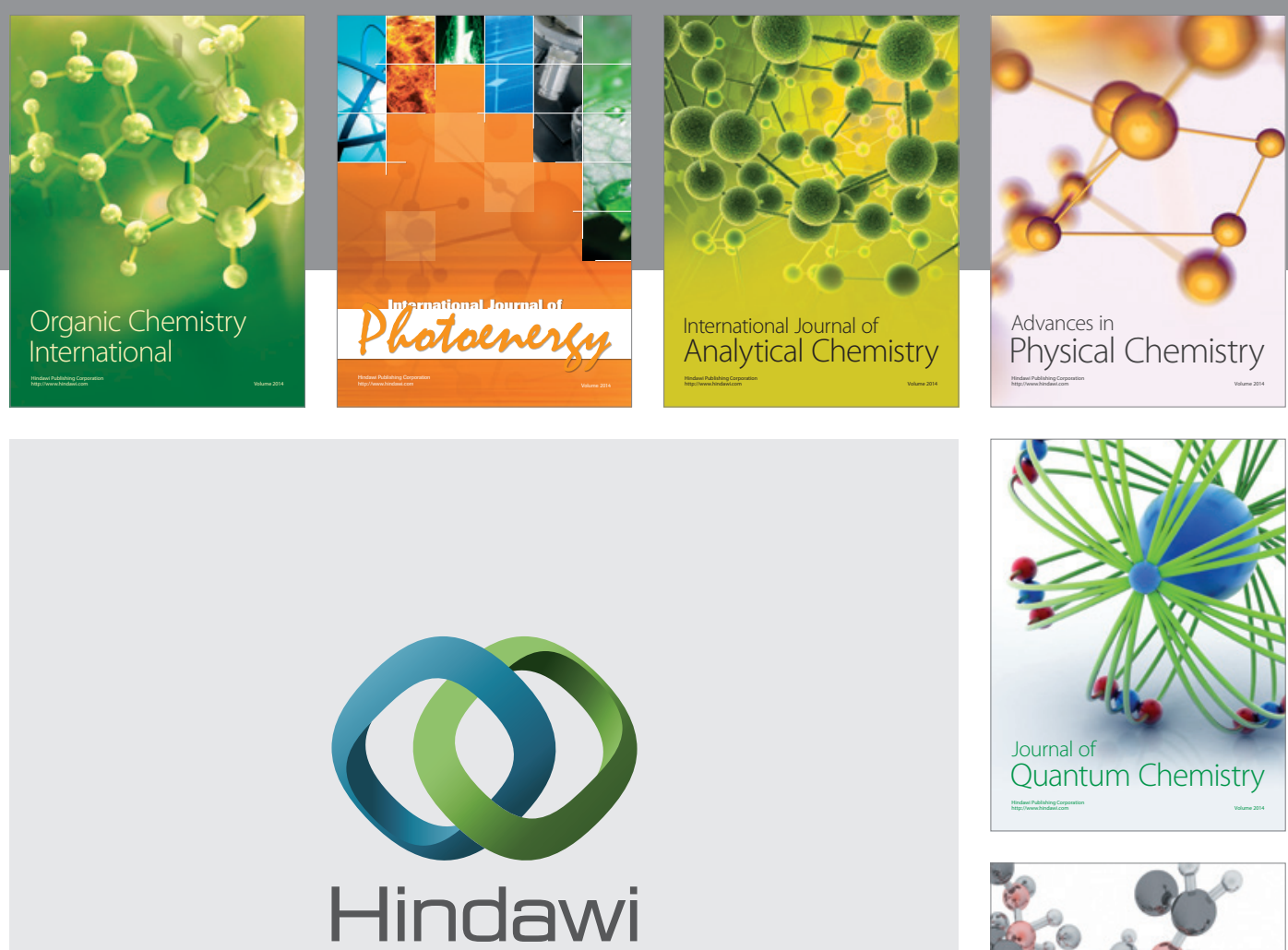

Submit your manuscripts at

https://www.hindawi.com

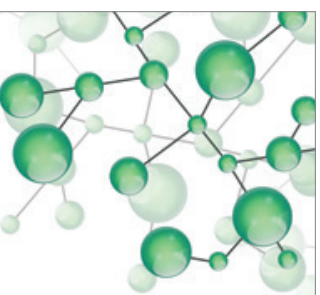

International Journal of

Inorganic Chemistry
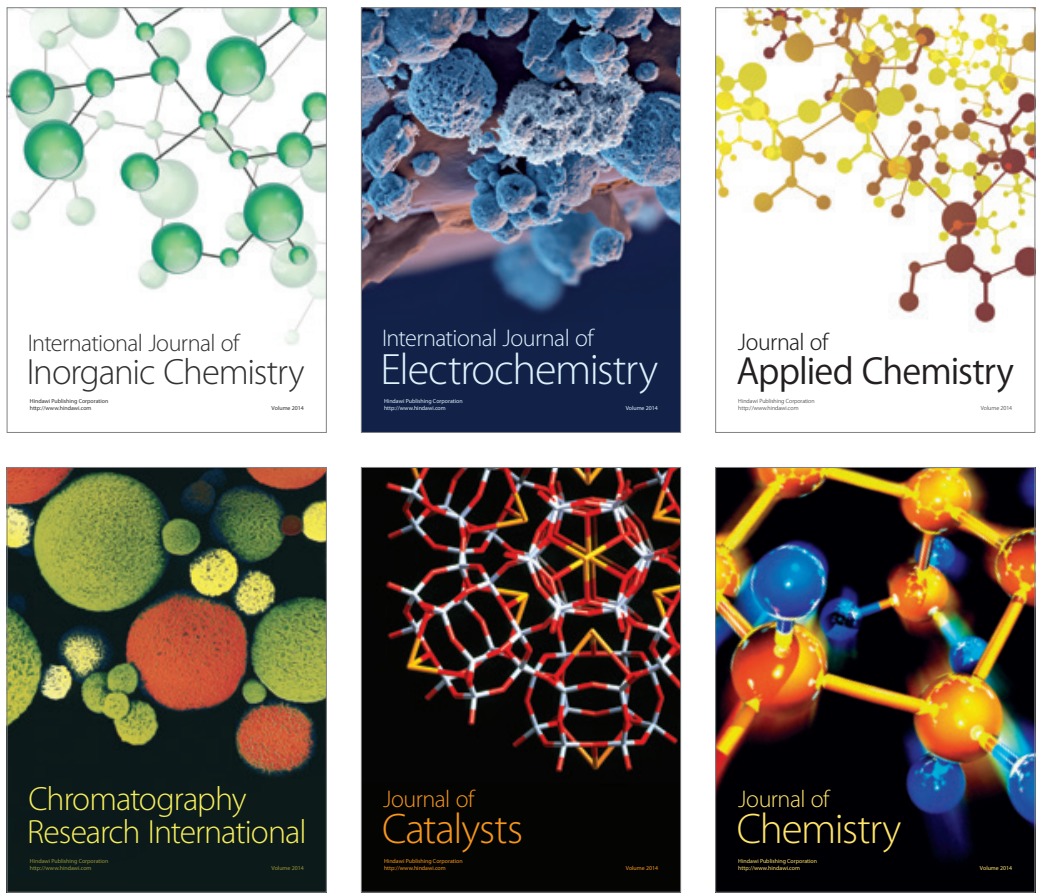

Journal of

Applied Chemistry
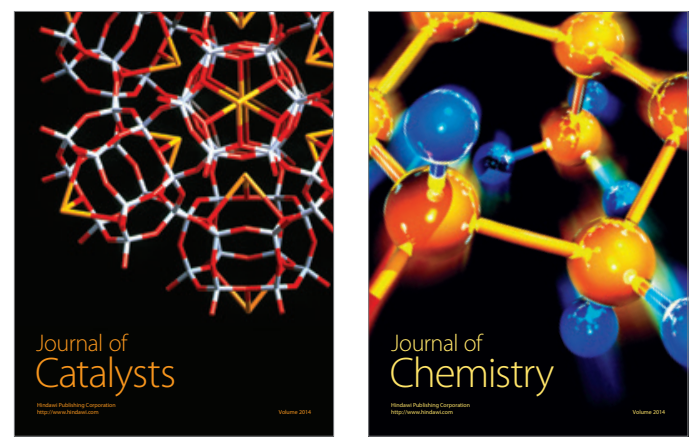
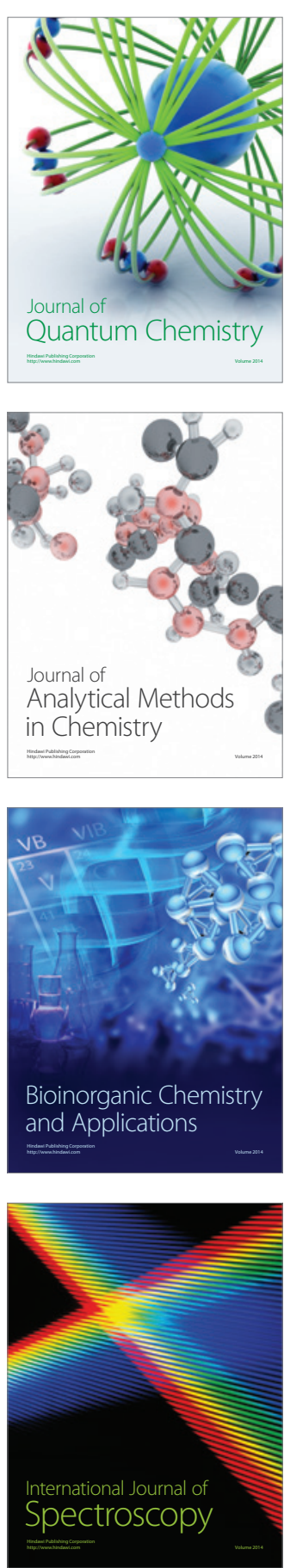